\title{
Cyclic Behavior of Steel Frames Infilled with Composite Panels: Experimental and Numerical
}

\author{
Hetao Hou, ${ }^{*}$, Canxing Qiu ${ }^{2}$,Zhonglong Lv ${ }^{1}$ and Yanfei Sun ${ }^{1}$ \\ ${ }^{1}$ School of Civil Engineering, Shandong University, Jinan 250061, P.R.China \\ ${ }^{2}$ School of Civil Engineering, Hongkong Polytechnic University, Hongkong , P.R. China
}

\begin{abstract}
For studying the hysteretic behavior of steel frames with sandwich composite (SC) panels, an experiment was implemented. A full scale one-bay and one storey specimen was tested under cyclic loading. Seismic behaviors were evaluated in line with the failure pattern and damage process of the specimen. Based on the experimental data, hysterics loops, skeleton curves, curves of strength degradation, and curves of stiffness degradation, ductility index and viscous damping coefficient were obtained. It is indicated that although the failures of panels mostly occurred around the embedded parts, SC panels exhibit a better integration than traditional walls. The connection between panel and steel frame is crucial to the corporation of the two parts. Finally, the suggestions for seismic design were put forward based on ductility index analysis and structures' energy dissipation. Moreover, FEA study was also carried out by using ABAQUS. A good agreeement was achieved between the experimental data and the numerical result in FEA. Finally, the useful information was got according to simplified caculation model. Only $7 \%$ of lateral stiffness is considered into calculation when panel is bolted to the frame at four corners of the frame,
\end{abstract}

Keywords: Composite panels, steel frames, cyclic loading tests, FEA; hysteretic behavior.

\section{INTRODUCTION}

Although infilled walls are non-structural parts, the lateral stiffness, ultimate strength and energy dissipation capacity of steel frames could be greatly improved with infilled walls. As internal partitions or external claddings, most of infilled frames with traditional walls are made of concrete or bricks. For aiming at exploring the characteristics of infilled frames, a great number of researches pay attention to infilled frames with in-plane forces.

Polyakov [1,2] carried out parameter analysis of 65 largescale infilled steel frames. The parameters were consisted of masonry units, mortar, method of loading and wall openings. Along with individual panels, a three-story, three-bay frame of one-quarter scale was also tested. According to the results, the multistory-multibay infilled frame behaved as a group of individually braced frames rather than a single monolith. The braced frame model was also confirmed by M.Papia and L.Cavaleri $[3,4]$. They defined a diagonal pin-jointed strut being able to represent the horizontal force-interstorey displacement cyclic law of the actual masonry infill. Different with previous empirical approaches, the proposed technique involves the axial stiffness of the columns of the frame more than their flexural stiffness. In order to support the results of analysis, an experimental investigation related to single story-single bay infilled reinforced concrete was carried out.

*Address correspondence to this author at the School of Civil Engineering, Shandong University, Jinan 250061, P.R.China; Tel: +86 13969036483;

E-mail: houhetao@sdu.edu.cn
A test on a two story one bay specimen under cyclic load was conducted by Peng and Gu [5,6], along with the nonlinear finite element analysis to study seismic behavior of the steel frame reinforced concrete infill walls. The study showed that reduction rotational stiffness of the connections, enhancement the width of infill walls, increasing numbers of horizontal headed studs, use general concrete and arranging reinforcement ratios of the concrete shear wall rationally would improve performance of the whole structure.

In spite of comprehensive literatures on steel frame, sandwich composite panels are seldom taken into consideration in previous researches [7-9]. With high ratio of strength to weight, good fire resistance performance, and excellent heat preservation capacity, the sandwich composite panel was useful to change characteristics of steel frame. The objective of this paper is to report an experimental investigation and finite element analysis on steel frame infilled with sandwich composite panel.

\section{EXPERIMENTAL RESEARCH}

\subsection{Description of Specimen}

In order to inspect the performance of infilled frame under earthquake-type loading, a full-scale one-bay and onestorey steel frame was manufactured and tested in the research. The columns of specimen were H-shaped steel sections of HW250 $\times 250 \times 9 \times 14 \mathrm{~mm}$ while the beams were $\mathrm{H}$ shaped steel sections of HN250 $\times 125 \times 6 \times 9 \mathrm{~mm}$. The characteristics of the specimen are summarized in Table 1 whereas a schematic of the test setup is shown in Fig. (1). The beam- 


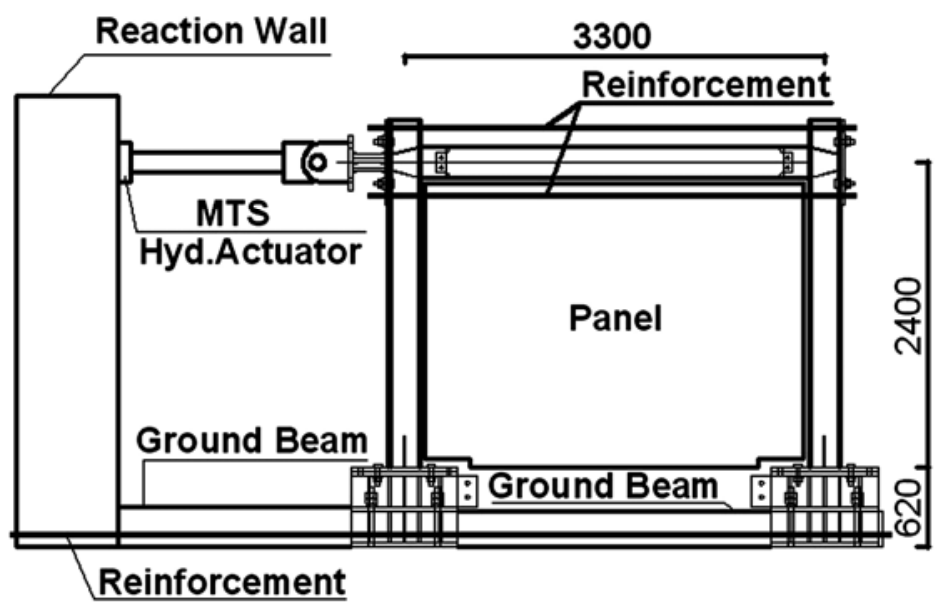

Fig. (1). Test set-up (dimensions in $\mathrm{mm}$ ).

Table 1. Characteristics of the Specimen

\begin{tabular}{|c|c|c|c|c|}
\hline Panel Thickness [mm] & Panel Type & Panel Position & Column Orientation & Beam-to-Column Connection Type \\
\hline \hline 140 & SC & Infilled & Strong & Welded flange-Bolted web \\
\hline
\end{tabular}

Notes: SC-Sandwich composite panel(as shown in Fig. (3)).

to-column joint of the specimen was welded flange-bolted web and the connection between the frame and the infill was achieved by using a steel plate that was welded on the column flange, and a bolt that was drawn into the embedded part in the panel, as shown in Fig. (2). The cube compressive strength of concrete cubes $(150 \mathrm{~mm} \times 150 \mathrm{~mm} \times 150 \mathrm{~mm})$ were tested at an average value of $26.5 \mathrm{~N} / \mathrm{mm}^{2}$, and the elastic modulus was $3.1 \times 10^{4} \mathrm{~N} / \mathrm{mm}^{2}$.

\subsection{Experimental Set-up and Testing Procedure}

With the purpose of loading the specimens, the closedloop servo-hydraulic system was utilized in experiment. The cyclic static displacement was imposed in the plane of the

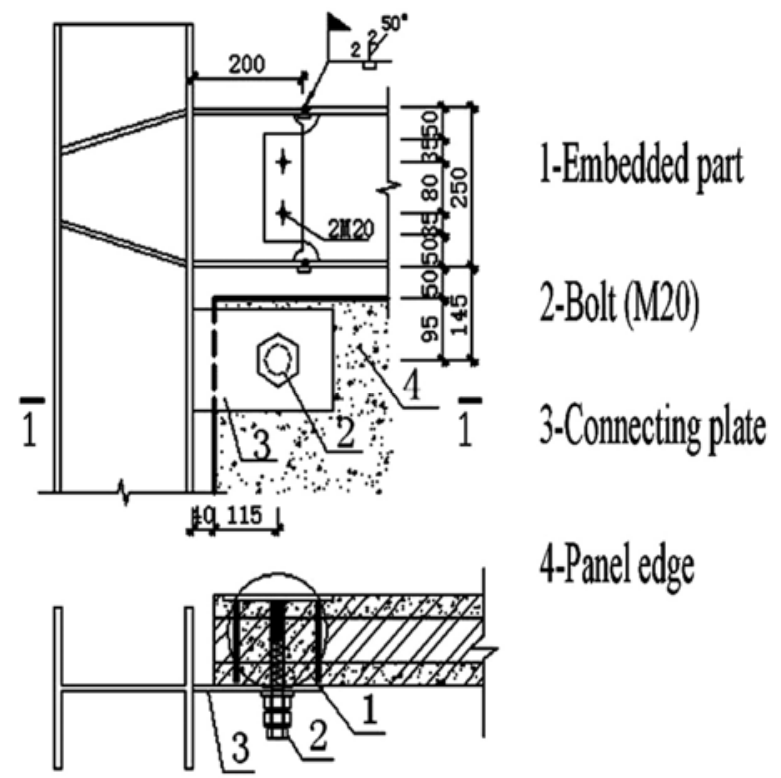

Fig. (2). Connections between frames and panels. wall at the center line of the beam. No axial load was applied. in the test, both in-plane and out-of-plane displacements were measured by linear variable differential transformers (LVDTs). The data were recorded by Portable Data Collection System. In line with ATC-24 [10] guidelines for cyclic testing of steel structures, the testing procedure was made and strictly followed as Fig. (4) shown. Suffice to note that the loading history was divided into elastic cycles and inelastic cycles. The experiment moved on until any of the following damage criteria occurred: (1) severe local buckling of beams or columns; (2) shearing of bolts; (3) large deformation or deflection of members; (4) corner crushing of panels; (5) throughout cracks on the surface of panels.

\section{EXPERIMENTAL RESULTS}

\subsection{Failure Modes}

The main experimental procedure of specimen subjected to cyclic displacement load is described as below: when the displacement of beam end reached $1.6 \mathrm{~mm}$ at the first cycle of $0.5 \Delta_{y}$, short small cracks appeared on the panel surface around the right-bottom and left-top embedded parts; when the displacement reached $2.4 \mathrm{~mm}$ at the second cycle, a $25 \mathrm{~cm}$ long vertical small crack was emerged in the middle part of panel surface. During the loading cycle of $2.0 \Delta_{y}$, with the displacement increased to $9.6 \mathrm{~mm}$ at the first cycle, the crack in the middle part of panel surface propagated to the top; meanwhile some $150 \mathrm{~mm}$ long cracks appeared on the panel surface around the left-bottom and right-bottom embedded parts, when the displacement reached $4.8 \mathrm{~mm}$ at the first cycle and $8.4 \mathrm{~mm}$ at the second cycle respectively. At the second cycle of $3.0 \Delta_{y}$, the specimen made a rattling sound, which may be caused by the friction between connecting plate and bolt. When the displacement increased to $22 \mathrm{~mm}$ at 


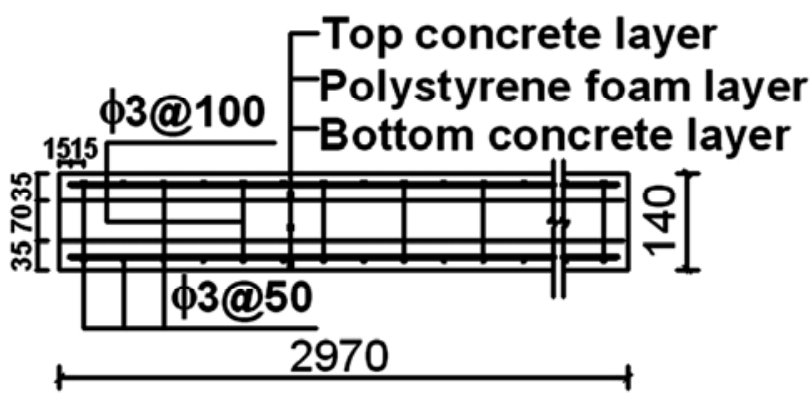

Horizontal section

Fig. (3). Section characteristics of SC panel.

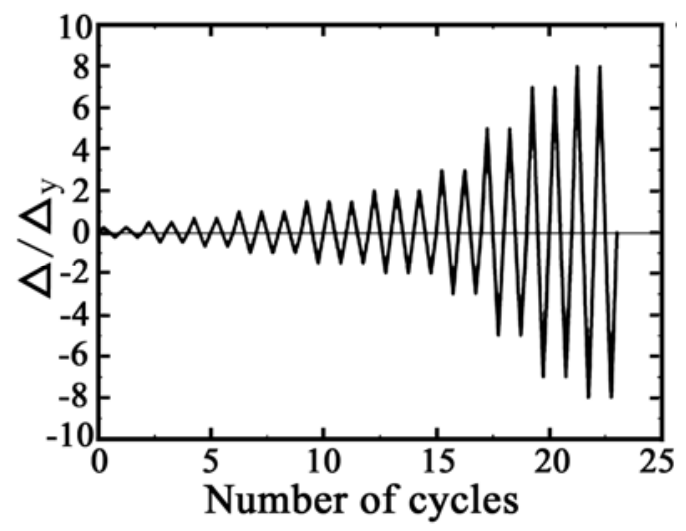

Fig. (4). Testing procedure.

the first cycle of $5 \Delta_{y}$, concrete spalling was found around the right-top and right-bottom embedded parts; and the spalling lasted to the end of the loading procedure. At the second cycle of $7 \Delta_{y}$, local buckling of bottom flange near weld occurred when the displacement reached $48 \mathrm{~mm}$, and with the displacement increased to $67.2 \mathrm{~mm}$, accompanied by loud popping noises, the right weld fractured at the bottom flange. At this moment, severe concrete spalling was found around the embedded parts; moreover, many cracks appeared on the panel surface. Due to the experimental phenomenon reached damage criteria, shown in Fig. (5,a-d), testing procedure was terminated.

Suffice to note, when the specimen was subjected to a horizontal load, the bolt slipped in the hole; however, the limited space $( \pm 10 \mathrm{~mm})$ restricted the relative slide between the connecting plate and bolt, hence interaction between

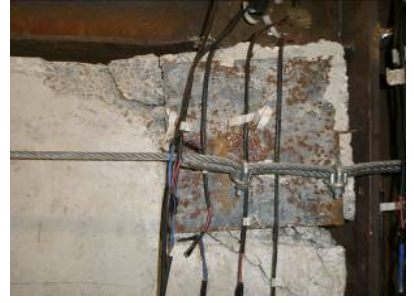

(a) Cracks and spalling

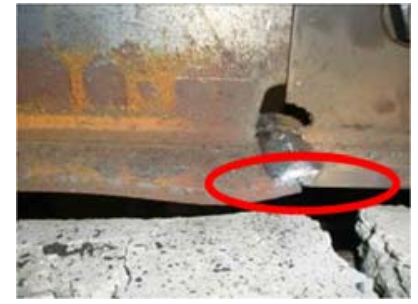

(b) Local buckling
Fig. (5, a-d). Failure pattern of specimen.

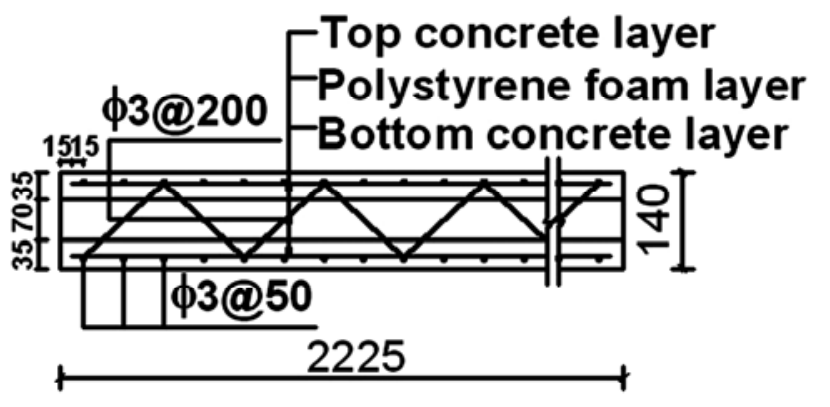

Vertical section

panel and steel frame was achieved. Now that mutual interaction was built, the steel frame resisted the load in cooperation with panel, so the initial lateral strength and initial lateral stiffness were increased. With loading increasing, diagonal cracks around the embedded parts appeared on the surface of panel, and then long cracks were observed in the middle of panel. The observation was significantly different from the previous literatures, in which the infill panel, such as brick infill, and masonry infill, generated large diagonal cracks across the panel. Therefore, as a precast concrete member, the composite panels exhibit a better integration than traditional walls. When the displacement increased from moderate level to high level, cracks around the embedded parts tend to dilate; namely cracks widen from cyclic loading along crack surfaces. As soon as cracks appeared, the forces transmitted from steel frame to panel were concentrated on the cracked region, followed by concrete spalling with the ongoing displacement. While for the rest part of panel, not only do no more new cracks appear, but also old cracks ceased to dilate. In the experiment, neither the connecting plate nor the embedded parts failed to keep working. These results showed that adequate detailing and proper construction of connection between steel frame and panel was achieved.

The $P-\Delta$ hysteresis loop of the specimen is shown in Fig. (6). It is indicated that the hysteresis loops exhibit pinching behavior in general. which is quite typical for infills. The pinching behaviour could be explained by concrete spalling around the embedded parts. The stiffness degradation is partly attributed to plastic deformation of the steel frame and mainly ascribe to deactivation of panel. Normally, concrete spalling around the embedded parts would lead to the connection between panel and steel frame transmit mutual forces partially if the lateral displacement was beyond

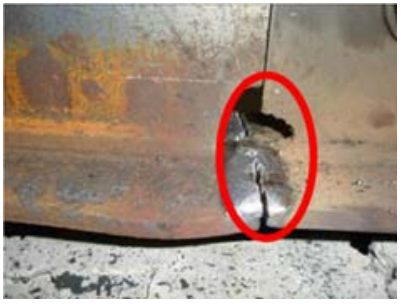

(c) Weld fracture

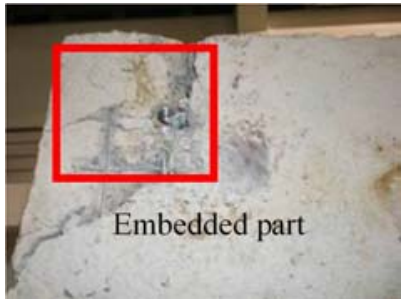

(d) Spalling 


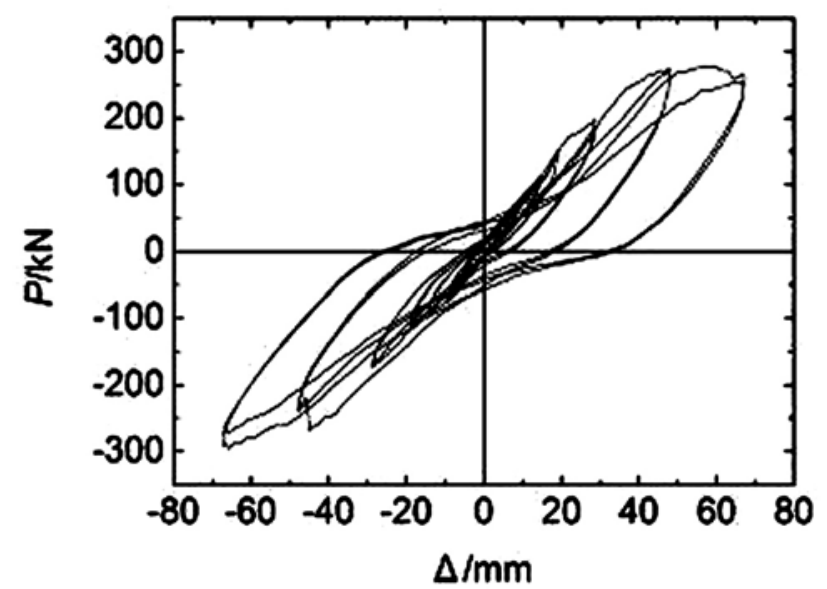

Fig. (6). $P-\Delta$ hysteresis loop.

the concrete can support. In this occasion, lower lateral stiffness was exhibited by the specimen gradually on account of unworkability of the panel.

Regarding to the skeleton curve presented in Fig. (7), it is constructed by connecting the peak value in each loading cycle. The skeleton curve is composed of two parts. The positive loading curve gives the hint that there is no obvious strength degradation of the specimen. The specimen strength keeps increasing till the end of experimentation. Meanwhile, the specimen maintains bearing capacity even if the member damage emerged. In fact, weld fracture, beam buckling and concrete spalling will lead to the member damage. Bearing capacity is dertermined by the degree of connection between the frame and the panel. In other aspect, the characteristic points of envelope curve are determined by using the given method in Fig. (8). The ultimate load is stipulated as $P_{u}=0.85 P_{\max }$, while the corresponding displacement is $\Delta_{u}$. With regard to Table 2, characteristic points of each specimen are presented. The ultimate displacement for specimen is $48 \mathrm{~mm}$, and the yielding displacement is about $5 / 12$ of the ultimate displacement.

\subsection{Strength Degradation and Stiffness Degradation}

The strength of test specimen degrades with increasing cycles of reverse loads. The characteristic of the strength degradation can be evaluated by the strength degradation coefficient at the same load $\left(\lambda_{j}\right)$ as well as at the total loads $\left(\lambda_{i}\right)$. The strength degradation coefficient at the same load $\left(\lambda_{j}\right)$ is expressed as:

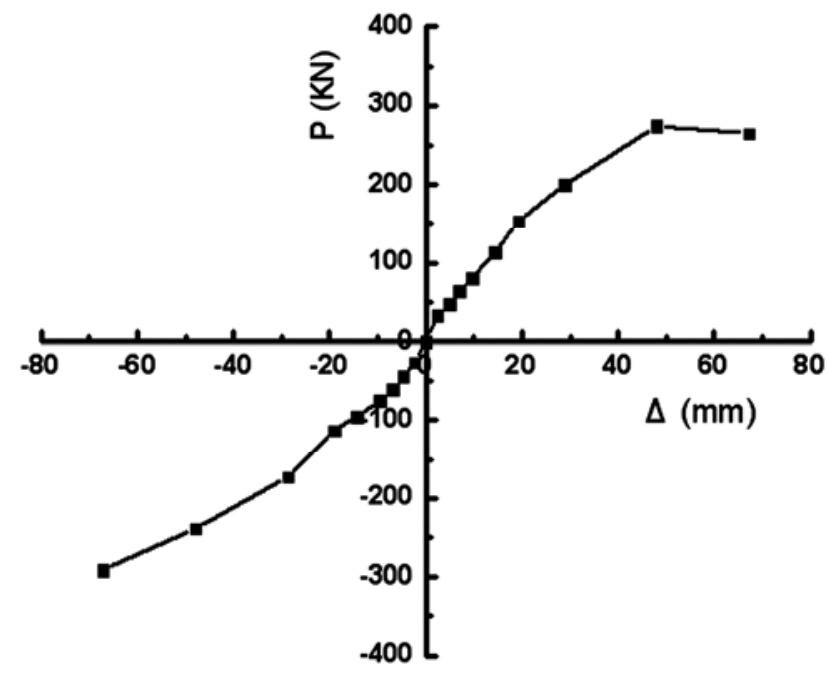

Fig. (7). Skeleton curve.

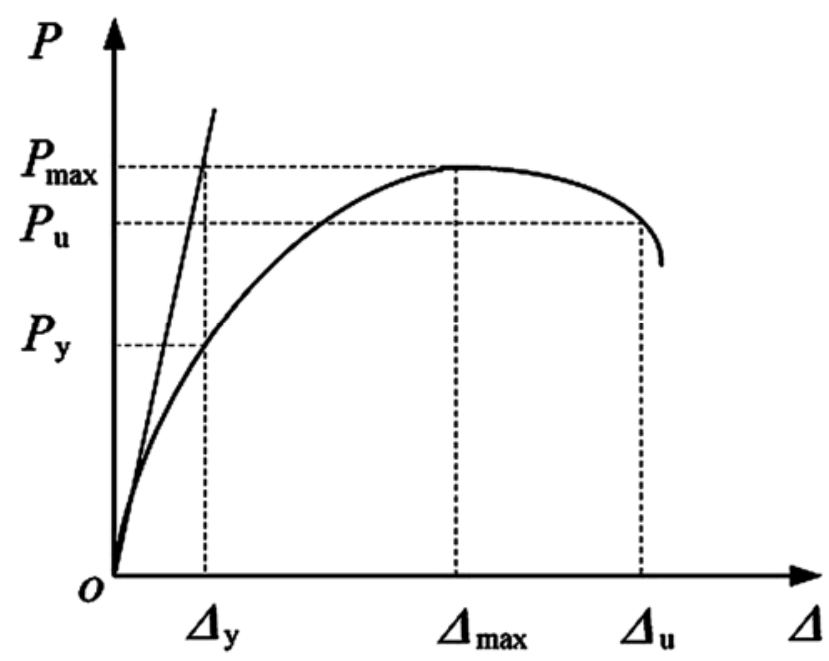

Fig. (8). Feature points.

$\lambda_{j}=\frac{P_{j}^{i}}{P_{j}^{1}}$

where $P_{j}^{i}$ and $P_{j}^{1}$ are respectively the maximum loads under the $i$ th and first loading cycles when the relative beam end displacement $\left(\Delta / \Delta_{y}\right)$ equals $j$.

The strength degradation coefficient at the total load $\left(\lambda_{i}\right)$ is expressed as:

$$
\lambda_{i}=\frac{P_{i}}{P_{\max }}
$$

Table 2. Characteristic Points and Ductility Coefficient of the Specimen

\begin{tabular}{|c|c|c|c|c|c|c|c|c|c|}
\hline \multicolumn{3}{|c|}{ Yielding point } & \multicolumn{2}{|c|}{ Maximum point } & \multicolumn{3}{|c|}{ Ultimate point } & \multirow{2}{*}{$\mu$} & \multirow{2}{*}{$\mu_{\theta}$} \\
\hline$\Delta_{y}[\mathbf{m m}]$ & $\theta_{y}$ [mrad] & $P_{y}[\mathbf{k N}]$ & $\Delta_{\max }[\mathrm{mm}]$ & $P_{\max }[\mathrm{kN}]$ & $\Delta_{u}[\mathrm{~mm}]$ & $\theta_{u}$ [mrad] & $P_{u}[\mathbf{k N}]$ & & \\
\hline 20.2 & 8.42 & 158.3 & 48 & 274.8 & 64.7 & 26.96 & 233.6 & 3.20 & 3.20 \\
\hline
\end{tabular}


where $P_{i}$ is the maximum load under the $i$ th loading cycles when the relative beam end displacement $\left(\Delta / \Delta_{y}\right)$ equals $i$; and $P_{\max }$ is the maximum load in the whole loading procedure.

Fig. (9) exhibits the $\lambda-\Delta / \Delta_{y}$ relationship of the specimen. The test results demonstrate that before the relative beam end displacement $\Delta / \Delta_{y} \leq 3, \lambda_{i}$ increases gradually with an increase of $\Delta / \Delta_{y}$; when $\Delta / \Delta_{y}>3, \lambda_{i}$ varies differently for each specimen with the increasing of the displacement, but the amplitude of variation is slight. This phenomenon shows that at the ultimate limit state the strength reduced slightly, namely the specimen still hold bearing capacity although the displacement was large.

In order to reflect the stiffness degradation of specimens under cyclic loading, the stiffness of specimens can be evaluated by the index-cyclic stiffness [11], which can be expressed as follows:

$K_{j}=\frac{\sum_{i=1}^{n} P_{j}^{i}}{\sum_{i=1}^{n} u_{j}^{i}}$

where $K_{j}$ is cyclic stiffness; $P_{j}^{i}$ and $u_{j}^{i}$ are the maximum beam load and the corresponding displacement respectively, under the $i$ th loading cycle when the relative beam displacement $\left(\Delta / \Delta_{y}\right)$ equals $j$, and $n$ is the number of cycles when the deformation is controlled as $u_{j}$.

It can be concluded from Fig. (10) that the initial lateral stiffness of specimen ranged from $1.1 \times 10^{4} \mathrm{kN} / \mathrm{m}$ to $1.4 \times 10^{4} \mathrm{kN} / \mathrm{m}$. With a slight increasing of displacement, the lateral stiffness decreased sharply, and the drastic descending trend extended to the relative displacement $\Delta / \Delta_{y}=1$. At the following portion, $K_{j}$ decreased slowly and steadily, reached the final value of $4 \times 10^{3} \mathrm{kN} / \mathrm{m}$, which is about $1 / 3$ of the initial value.

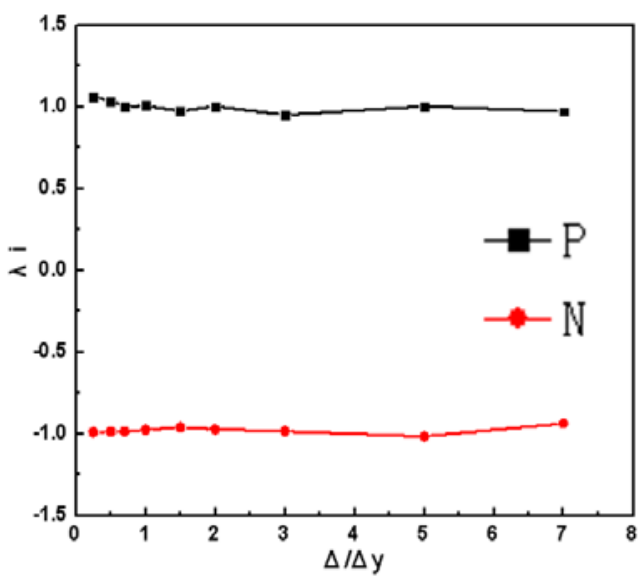

(a) Strength degradation curves at the same load

Fig. (9). Curves of strength degradation. P-positive N-negative.

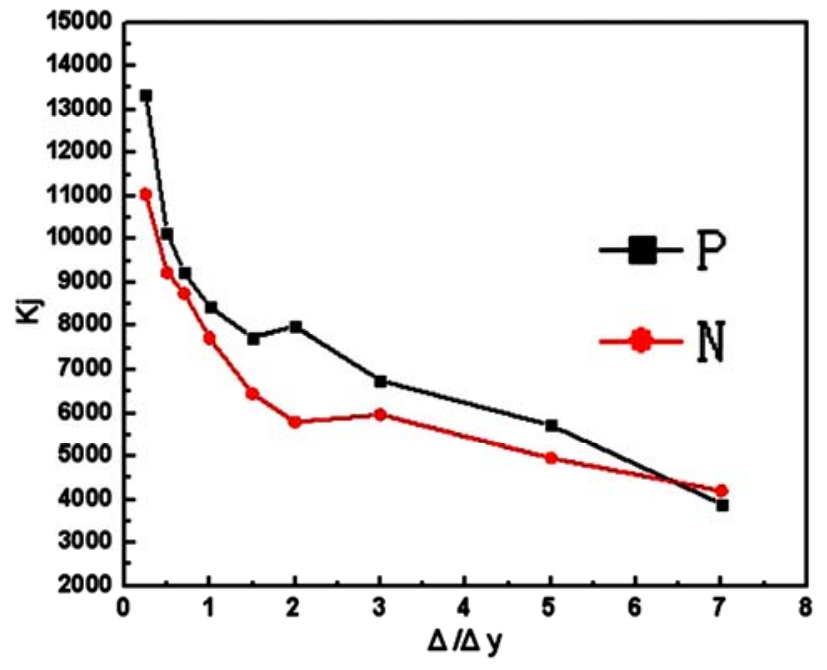

Fig. (10). Curves of stiffness degradation P-positive N-negative.

\subsection{Ductility Coefficient}

In line with previous researches, the ductility of the infilled steel frame with seismic loading has to be taken into consideration when to caculate the displacement ductility coefficient and angular ductility coefficient. The displaycement ductility coefficient $\mu$ is defined as

$\mu=\Delta_{u} / \Delta_{y}$

where $\Delta_{u}$ is the ultimate displacement and $\Delta_{y}$ is the yielding displacement.

The angular displacement $\mu_{\theta}$ can be expressed as

$\mu_{\theta}=\theta_{u} / \theta_{y}$

where $\theta_{u}=\arctan \left(\Delta_{u} / H\right) ; \theta_{y}=\arctan \left(\Delta_{y} / H\right)$ and $H$ is the column height. These parameters are summarized in Table 2. According to Chinese Code for seismic design of buildings GB50011-2010 [12], the elastic story drift ratio $\left[\theta_{e}\right]=1 / 250=$

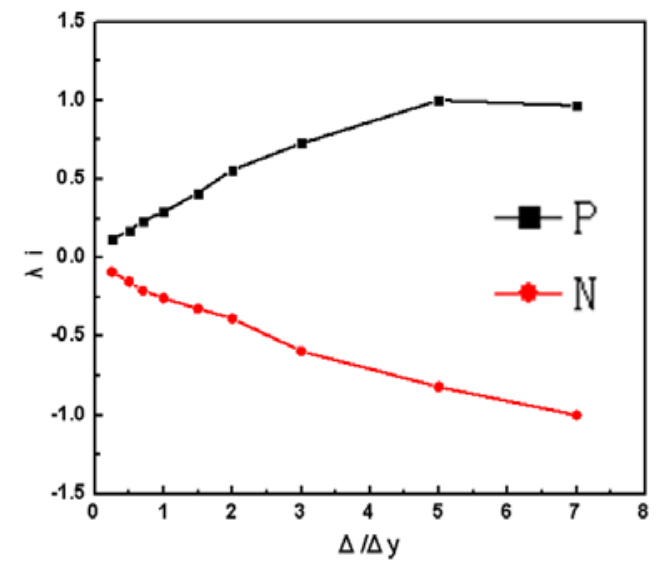

(b) Strength degradation curves at the total load. 
$0.004 \mathrm{rad}$, while the elastic-plastic layer angular $\left[\theta_{p}\right]$ $=1 / 50=0.02 \mathrm{rad}$. It is indicated in Table 2 , the displacement ductility coefficient of the specimen $\mu \approx 3.20$, the elastic yielding angular ductility coefficient $\theta_{y} \approx 2.53\left[\theta_{e}\right]$, and the elastic-plastic angular ductility coefficient $\theta_{u} \approx 1.35\left[\theta_{p}\right]$. Accordingly, the infilled steel frame meets the requirement of Chinese Code for seismic design of buildings because of the excellent ductility demonstrated.

\subsection{Energy Dissipation Capacity}

The equivalent damping coefficient $\left(\xi_{e}\right)$ is adopted to analyze the energy dissipation capacity of the infilled steel frame. According to the $P-\Delta$ relationship shown in Fig. (11), $\xi_{e}$ can be calculated by Eq. (6). It is demonstrated in Fig. (11), $\mathrm{S}_{\mathrm{ABC}}$ and $\mathrm{S}_{\mathrm{CDA}}$ are areas enclosed by curves $\mathrm{ABC}$ and CDA respectively, while $\mathrm{S}_{\mathrm{OBE}}$ and $\mathrm{S}_{\mathrm{ODF}}$ are areas within triangles OBE and ODF respectively.

$\xi_{e}=\frac{1}{2 \pi} \frac{S_{A B C}+S_{C D A}}{S_{O B E}+S_{O D F}}$

The dissipated energy capability $(E)$ of each hysteretic loop is also used to evaluate the energy dissipation capacity, $E$ is expressed as $E=2 \pi \cdot \xi_{e}$.

Just as what indicated in Fig. (12) and Table 3: (1) The $\xi_{e}-\Delta / \Delta_{y}$ relationship could be explained as two parts. In first phase, dramatic decreasing of the lateral stiffness increases displacement, so that $\xi_{e}$ drops as well. In the second

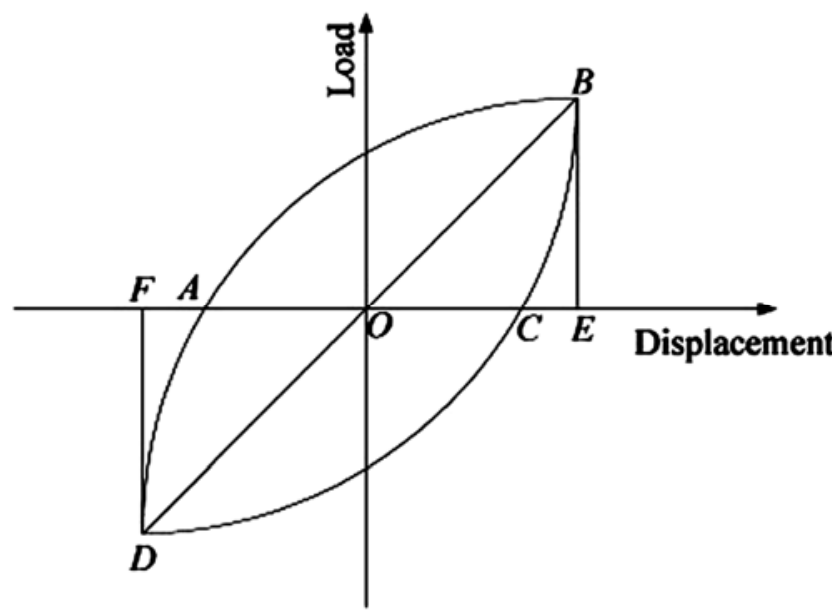

Fig. (11). $P-\Delta$ relationship.

Table 3. Energy Dissipated Coefficients of the Specimen stage, when $\Delta / \Delta_{y} \geq 2, \xi_{e}$ increases with increasing displacement. In this phase, the curve reflects the plastic formation of steel frame because the severely damaged panel is gradually quitting action. (2) At the yielding state, $\xi_{e}$ is close to 0.0878 . The maximum value of $\xi_{e}$ is about 0.132 . At the end of yielding phase, $\xi_{e}$ is about 0.144 .

\section{NUMERICAL STUDIES}

Numerical studies were carried out by ABAQUS. For numerical analysis, the concrete was defined as damaged plasticity. The specific material properties of concrete were summarized in Table 4. Meanwhile, the Guo [13] model was adopted to simulate the compressive and tensile behavior of concrete. The compressive behavior was described as follows:

$y(x)= \begin{cases}\alpha_{a} x+\left(3-2 \alpha_{a}\right) x^{2}+\left(\alpha_{a}-2\right) x^{3} & x \leq 1 \\ \frac{x}{\alpha_{d}(x-1)^{2}+x} & x>1\end{cases}$

where, $\quad \alpha_{a}$-ascending parameter, $\alpha_{a}=E_{c} / E_{0}$, generally, $1.5 \leq \alpha_{a} \leq 3 ; \alpha_{d}$-decreasing parameter. The testing data were listed in Table 5

The tensile behavior was described as follows:

$y(x)= \begin{cases}\frac{\sigma}{f_{t}}=1.2 x-0.2 x^{6} & 0 \leq x=\frac{\varepsilon}{\varepsilon_{t 0}} \leq 1 \\ \frac{\sigma}{f_{t}}=\frac{x}{\alpha_{t}(x-1)^{1.7}+x} & x=\frac{\varepsilon}{\varepsilon_{t 0}}>1\end{cases}$

where, $\varepsilon_{t 0}$-peak strain, $\varepsilon_{t 0}=0.65 f_{t}^{0.54} \times 10^{-4}, \alpha_{a}=0.312 f_{t}^{2}$;

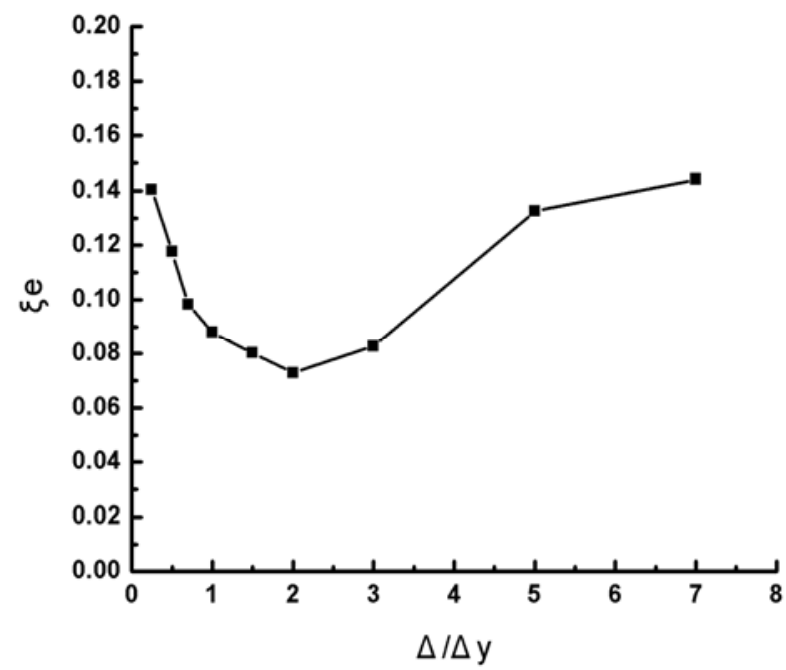

Fig. (12). Relationship between $\xi_{e}$ and displacement.

\begin{tabular}{|c|c|c|c|}
\hline Status & Total Dissipated Energy $[N \cdot m]$ & Equivalent Damping Coefficient $\xi_{e}$ & Dissipated Energy Capability $\boldsymbol{E}$ \\
\hline \hline Maximum & 10225 & 0.132 & 0.829 \\
\hline Ultimate & 16984 & 0.144 & 0.904 \\
\hline
\end{tabular}


Table 4. Material Properties of Concrete

\begin{tabular}{|c|c|c|c|c|c|}
\hline Dilation Angle & Eccentricity & $\boldsymbol{f}_{\mathrm{b} 0} / \boldsymbol{f}_{\mathrm{c} 0}$ & $\boldsymbol{K}$ & Viscous parameter & $\boldsymbol{E}\left(\mathbf{N} / \mathbf{m}^{2}\right)$ \\
\hline \hline 30 & 0.1 & 1.16 & 0.667 & 0 & \\
\hline
\end{tabular}

Table 5. Compressive Stress-Inelastic Strain of Concrete

\begin{tabular}{|c|c|c|c|c|c|c|c|c|c|c|}
\hline Compressive stress(MPa) & 20.46 & 24.42 & 26.268 & 26.532 & 25.872 & 23.64 & 21.8 & 21.278 & 20.51 & 9.1 \\
\hline Inelastic stain & 0 & $9.98 \mathrm{e}-4$ & 0.0014 & 0.00166 & 0.00176 & 0.0019 & 0.00215 & 0.00245 & 0.00275 & 0.00542 \\
\hline
\end{tabular}

Table 6. Tensile Stress-Cracking Strain of Concrete

\begin{tabular}{|c|c|c|c|c|c|c|c|c|}
\hline Tensile stress(MPa) & $\mathbf{2 . 3}$ & $\mathbf{2 . 6}$ & $\mathbf{2}$ & $\mathbf{1 . 6}$ & $\mathbf{1 . 2 3}$ & $\mathbf{1 . 1 8}$ & $\mathbf{0 . 8 5}$ & $\mathbf{0 . 6 2}$ \\
\hline \hline Cracking stain & 0 & $1.90 \mathrm{e}-5$ & $5.00 \mathrm{e}-05$ & $1.02 \mathrm{e}-04$ & $1.70 \mathrm{e}-04$ & $2.10 \mathrm{e}-04$ & $2.60 \mathrm{e}-04$ & $2.90 \mathrm{e}-04$ \\
\hline
\end{tabular}

The testing data were listed in Table 6.

A simplified numerical model explored and developed in the research is shown in Fig. (13). In order to converge the numerical results, it is presumed in the model that the surrounding concrete was elastic concrete. Comparing with the experimental data, a good agreement could be achieved and indicated in Fig. (14).

\section{SIMPLIFIED CALCULATION FORMULA}

In some cases, because the contact between frame and the panel will lead to the variation of mechanical property of the whole specimen, the capability of resisting lateral deformation is not equal to the sum of the capability of each part. Therefore, one tie model is presented in the research to simulate the lateral stiffness. The simplified model is shown in Fig. (15).

$D_{i}=D_{d}+D_{f}$

Fig. (16). indicates the decomposition of lateral stiffness, which is described as follows.

where the $D_{\mathrm{i}}$ is lateral stiffness of the whole specimen; $D_{\mathrm{d}}$ is

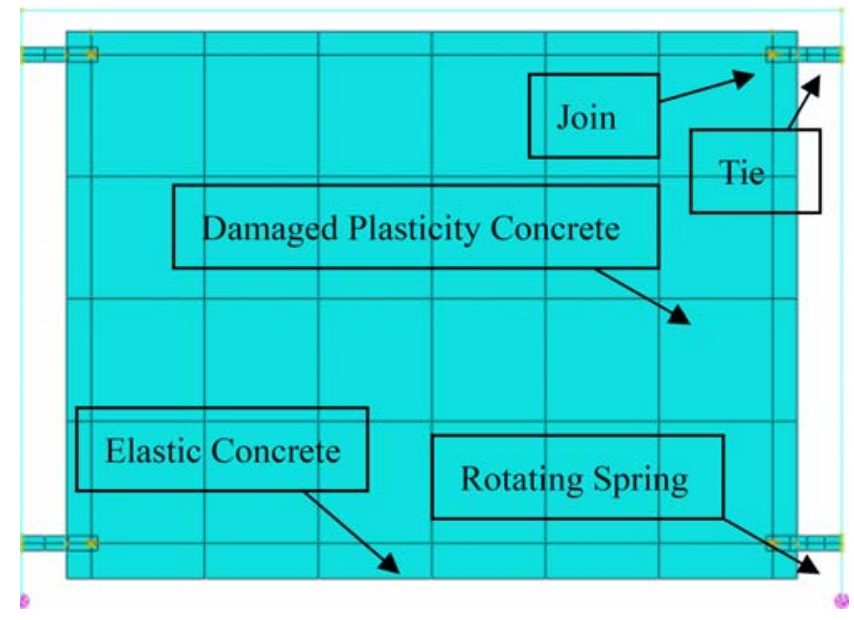

Fig. (13). Numerical model. the additional stiffness added by panel; $D_{\mathrm{f}}$ is the lateral stiffness of the bare frame. $D_{\mathrm{d}}$ shown in Fig. (17). is described as follows:

$$
D_{d}=\frac{k_{d} \cos ^{2} \theta}{1+\frac{k_{d}}{k_{c}} \sin ^{2} \theta}
$$

where $k_{d}=E_{d} t w / d, k_{c}=E_{f} A_{c} / H, k_{b}=E_{f} A_{b} / L ; k_{d}, k_{c} \mathrm{a}$ nd $k_{b}$ are the axial stiffness of the tie, frame column and frame beam respectively; $E_{\mathrm{d}}$ and $E_{\mathrm{f}}$ are the elastic modulus of panel and frame; $t$ is the thickness of wall panel; $w$ is the width of the tie; $A_{c}$ and $A_{b}$ are the cross section of the beam above the column and panel respectively; $H$ is the height of the frame; $L$ is the span of the frame beam; $d$ is the length of the diagonal of the panel. The lateral stiffness of the frame with panel is described as:

$$
D_{w}=\alpha \frac{1}{\frac{h^{3}}{3 E I}+\frac{2.4 h(1+v)}{E A}}
$$

where $\alpha$ is the reduction factor of stiffness of the wall

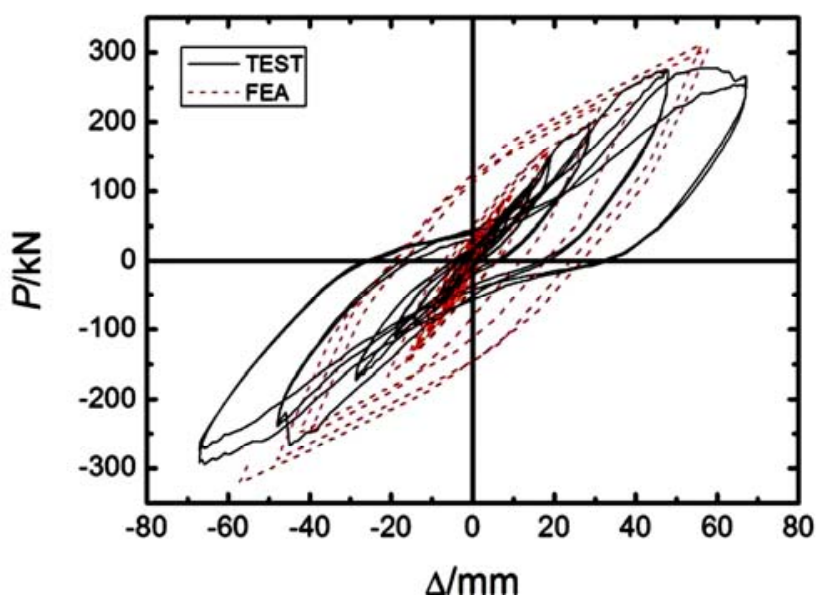

Fig. (14). Comparison between the results. 


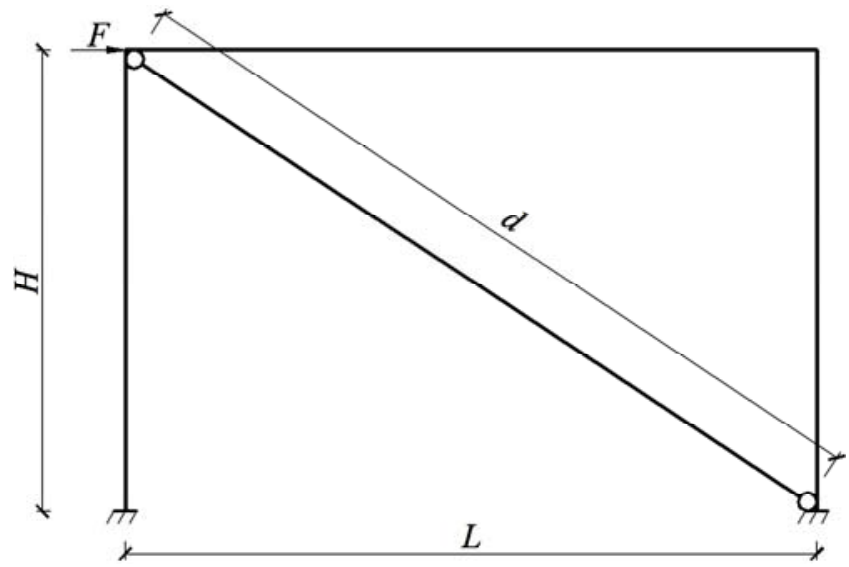

Fig. (15). Simplified model.

panel; $E$ is elastic modulus of the panel. The reataion of $E$ and $G$ should be $E / G=2(1+v)$, where $G$ is the shear modulus of elasticity, $v$ is the Poisson's ratio of material of the panel; $A$ and $I$ are area of cross section and moment of inertia of the panel respectively.

Equal Equation (10) to Equation (11), we can obtain

$$
\lambda=\frac{w}{d}=\frac{1}{E_{d} t\left(\frac{\cos ^{2} \theta}{D_{w}}-\frac{1}{k_{c}} \sin ^{2} \theta\right)}
$$

Based on checking calculation and verification, reduction factor $\alpha=0.07$ is adopted according to equivalent stiffness principle, namely $7 \%$ of the lateral stiffness of the panel is considered when it is bolted to the frame at four corners of the frame. Just as what indicated in Fig. (18), the results of simplified calculation methods agree well with experimental data.

\section{CONCLUSIONS}

In the light of the reliable experiment and the through numerical analysis, some helpful conclusions are drawn as following:

(1) The main failure modes of composite panel infilled steel frame include the concrete spalling around the embedded parts, the local buckling of beam flange and weld fracture of beam.

(2) Generally, the initial lateral stiffness of infilled frame range from $1.1 \times 10^{4} \mathrm{kN} / \mathrm{m}$ to $1.4 \times 10^{4} \mathrm{kN} / \mathrm{m}$, and the final value is about $1 / 3$ of the initial value.

(3) The displacement ductility coefficient of the test specimens $\mu \approx 3.20$, the elastic yielding angular ductility coefficient $\theta_{y} \approx 2.53\left[\theta_{e}\right]$, and the elastic-plastic angular ductility coefficient $\theta_{u} \approx 1.35\left[\theta_{p}\right]$.

(4) At the yielding phase, the equivalent damping coefficient $\xi_{e}$ is about 0.0878 ; at the maximum state, $\xi_{e}$ is about 0.132 ; at the final or ultimate state, $\xi_{e}$ is about 0.144 .

(5) Finite element analysis was carried out by using ABAQUS, and a simplified model was built to simulate the steel frame infilled with composite panel. Comparison was made between the experimental data and numerical result, and a good agreement can be found.
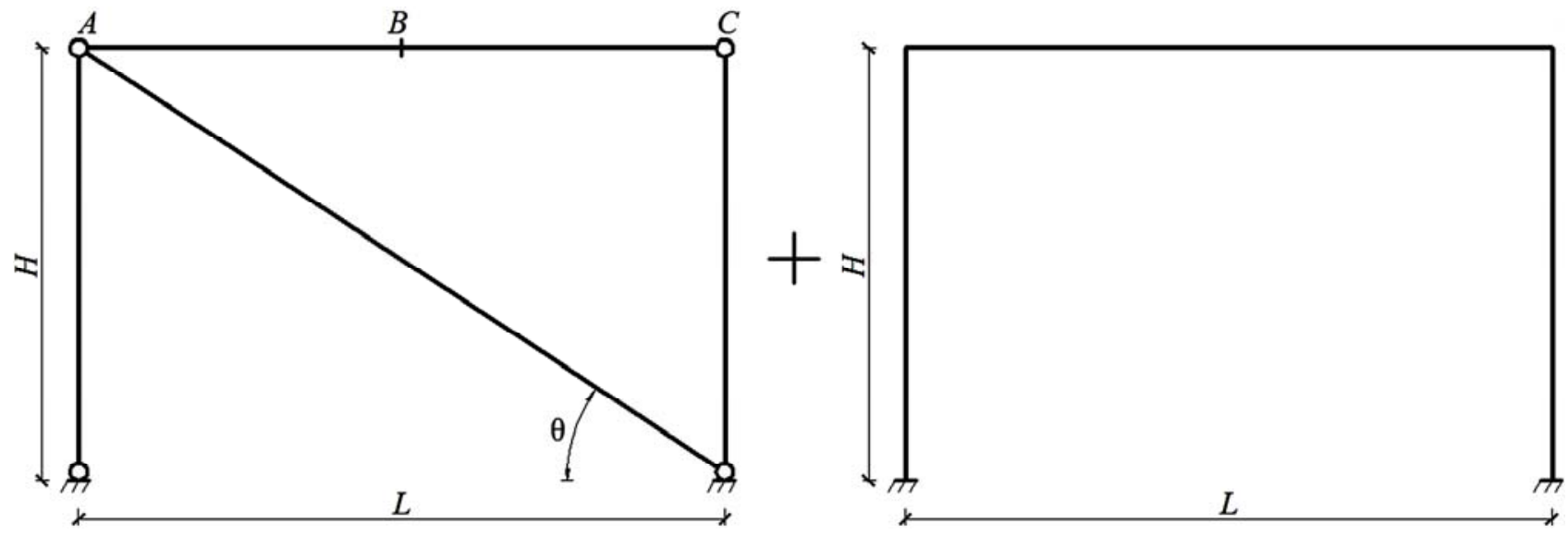

Fig. (16). Decomposition of lateral stiffness.
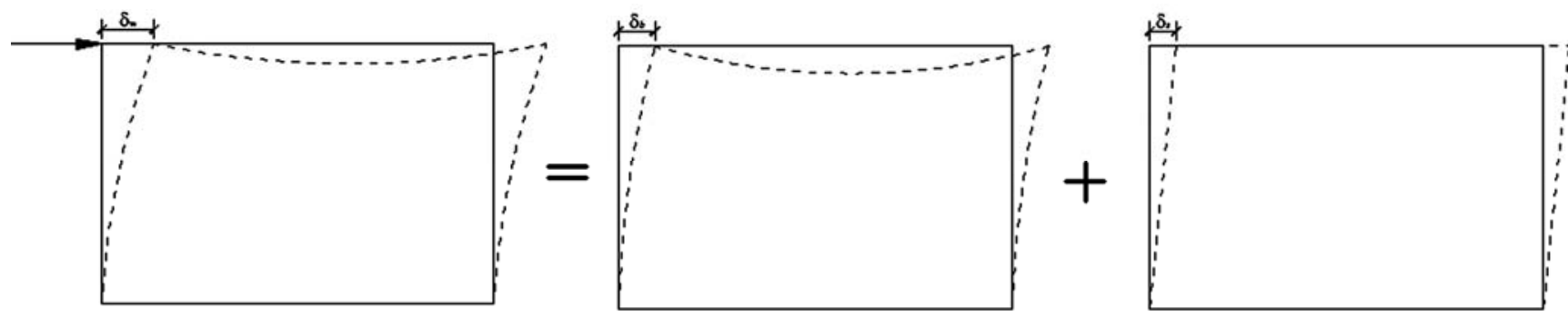

Fig. (17). Lateral stiffness of panels. 


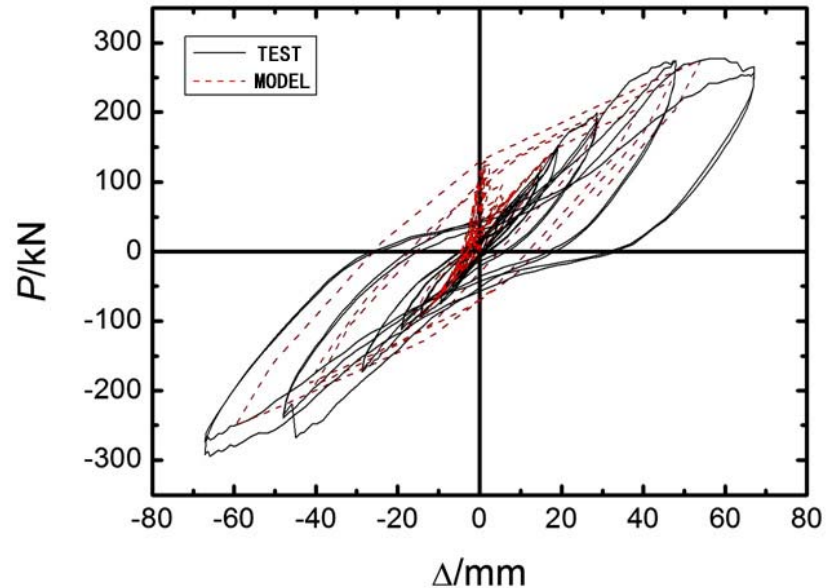

Fig. (18). Comparison between simplified model and real structure.

\section{CONFLICT OF INTEREST}

The authors confirm that this article content has no conflicts of interest.

\section{ACKNOWLEDGEMENTS}

This paper was supported by the Natural Science Foundation of Shandong Province, China (ZR2011EEM023) and the Graduate Education Innovative Projects of Shandong Province, China (SDYC11006).

\section{REFERENCES}

[1] S. V. Polyakov, "On the interaction between masonry filler walls and enclosing frame when loaded in the plane of the wall". Translations in earthquake engineering. Earthquake Engineering Research Institute: San Francisco, 1960, pp. 36-42.

[2] S. V. Polyakov, Masonry in framed buildings. G.L. Cairns, translator), National Lending Library for Science and Technology, Boston Spa, Yorkshire, U.K.1963

[3] M. Papia, L. Cavaleri, and M. Fossetti, "Infilled frames: developments in the evaluation of the stiffening effects of infills", Structural Engineering and Mechanics, vol. 16, no.6, pp. 675-693, 2003.

[4] L. Cavaleri, M. Fossetti, and M. Papia, "Infilled frames: developments in the evaluation of cyclic behaviour under lateral load", Structural Engineering and Mechanics, vol. 21, no.4, pp. 469-494, 2005.

[5] X. Peng, Q. Gu, and C. Lin, "Experimental study on steel framereinforced concrete infill wall structures with semi-rigid joints", China Civil Engineering Journal, vol. 41, no. 1, pp. 64-69, 2008. [In Chinese]

[6] X. Peng, Q. Gu, and C. Lin, "Hysteretic behavior analysis of steel frame-reinforced concrete infill wall structure with semi-rigid joints", Journal of Building Structures,vol. 30, no. 1, pp. 48-54, 2009. [In Chinese]

[7] H. D. Wright, and S. C. Gallocher, "The behaviour of composite walling under construction and service loading", Journal of Constructional Steel Research, vol.35, no. 3, pp. 257-273, 1995.

[8] A. Hanaor, "Experimental investigation of composite shear panels under cyclic loading", Journal of Constructional Steel Research, vol. 61 , no. 3 , pp. $345-369,2005$.

[9] G. De Matteis, and R. Landolfo, "Modelling of lightweight sandwich shear diaphragms for dynamic analyses", Journal of Constructional Steel Research, vol. 53, no. 1, pp. 33-61, 2000.

[10] ATC-24. Guidelines for cyclic seismic testing of components of steel structures. Applied Technology Council: Redwood City (CA), 1992.

[11] J. R. Tan, Seismic resistance of joints in reinforced concrete frames. Southeast Univ. Press: Nanjing (China), 1989[In Chinese].

[12] GB50011-2010. Code for seismic design of buildings. China Building Industry Press; Beijing, 2010 [In Chinese].

[13] Guo Zhenhai. Theory of reinforced concrete menmbers. Tsinghua University Press: Beijing, 1999.(in Chinese).

(C) Hou et al.; Licensee Bentham Open.

This is an open access article licensed under the terms of the Creative Commons Attribution Non-Commercial License (http://creativecommons.org/licenses/by-nc/3.0/) which permits unrestricted, non-commercial use, distribution and reproduction in any medium, provided the work is properly cited. 